\title{
DIELECTRIC PROPERTIES OF ELECTRON BEAM EVAPORATED SAMARIUM OXIDE FILMS
}

\section{K. JAYARAJ * AND C. P. G. VALLABHAN}

Deparmment of Phy:sicx. Cochin Unjuer.sity of Science and Technology. Cochin 682022 (India)

(Received May 15, 1990; accepted September 11. 1990)

The dielectric properties of electron beam evaporated $\mathrm{Sm}_{2} \mathrm{O}_{3}$ films have been investigated in the frequency range from $1 \mathrm{kHz}$ to $1 \mathrm{MHz}$ at various temperatures $(300 \mathrm{~K}-453 \mathrm{~K})$. The dielectric constant is found to depend on film thickness and it attains a constant value beyond $1000 \AA$. The present electron beam evaporated $\mathrm{Sm}_{2} \mathrm{O}_{3}$ films have a high dielectric constant of 43 . The frequency dependence of $\varepsilon$ and $\tan \delta$ at various temperatures is also studied.

\section{INTRODUCTION}

Rare earth oxide films have been studied previously ${ }^{1-5}$ with a view to using them in thin film capacitors in which the required degree of perfection varies according to specific application. Rare earth oxide films are also increasingly being used now as insulators in thin film electroluminescent devices ${ }^{6,7}$. A dielectric constant of 7-30 and relatively low dissipation factors of $0.55 \%-2.5 \%$ are reported for oxides of lanthanum ${ }^{8}$, cerium ${ }^{9}$, dysprosium ${ }^{10}$ and erbium ${ }^{1}$. The dielectric properties of rare earth oxide films are found to change with annealing or aging and they require annealing for $200 \mathrm{~h}$ to have stable dielectric properties. ${ }^{3}$. In the present paper we discuss the dielectric properties of $\mathrm{Sm}_{2} \mathrm{O}_{3}$ films prepared at a higher substrate temperature which remain stable during annealing and aging.

\section{EXPERIMENTAL DETAILS}

High purity $\mathrm{Sm}_{2} \mathrm{O}_{3}(99.99 \%)$ powder was deposited by electron beam evaporation onto thoroughly cleaned glass substrates maintained at a temperature of $453 \mathrm{~K}$. Vacuum-evaporated aluminium ( $99.99 \%)$ films form the front and back electrodes in a metal-insulator-metal structure. After deposition, the $\mathrm{Sm}_{2} \mathrm{O}_{3}$ films are subjected to annealing for $1 \mathrm{~h}$ at $453 \mathrm{~K}$ under a $10^{-5}$ Torr pressure. The electrical measurements were carried out under vacuum $\left(10^{-3} \mathrm{Torr}\right)$. The temperature was monitored using a chromel-alumel thermocouple. The capacitance and loss factors were measured over a frequency range from $1 \mathrm{kHz}$ to $1 \mathrm{MHz}$ and temperatures of

* Present address: Physical Research Laboratory, Navrangpura, Ahmedabad 380009, India. 
$300-453 \mathrm{~K}$ for various film thicknesses $(0.05-0.25 \mu \mathrm{m})$ using a 0.1 universal bridge and LCZ bridge (Hewelett-Packard model $4277 \mathrm{~A}$ ) range. The dielectric constant was evaluated from capacitance measurement data and knowledge of the thickness and area. The film thickness was measured using Tolansky's interference method.

\section{RESULTS AND DISCUSSION}

Figure $I$ shows the variation in dielectric constant $\varepsilon$ and loss factor $\tan \delta$ as a function of dielectric film thickness. The dielectric constant $\varepsilon$ is deduced from the equation $C=\varepsilon_{0} \varepsilon A / t$ where $\varepsilon_{0}$ is the permittivity of free space while the capacitance $C$, effective area $A$ and film thickness $t$ are measured values. The dielectric constant is found to increase with dielectric film thickness and attains a constant value of 43 for film thicknesses greater than $1000 \AA$. The loss factor of 0.02 is independent of film thickness. A similar thickness dependence is also observed for films of other rare earth oxides. It is also observed that films prepared at a substrate temperature of $300 \mathrm{~K}$ exhibit marked variation in $\varepsilon$ and $\tan \delta$ with aging time. These films require prolonged annealing to have a stable dielectric constant and $\tan \delta$, while the films prepared at a substrate temperature of $423 \mathrm{~K}$ have stable dielectric properties. The films prepared at higher substrate temperatures exhibit better dielectric properties owing to the improved stoichiometry of the films.

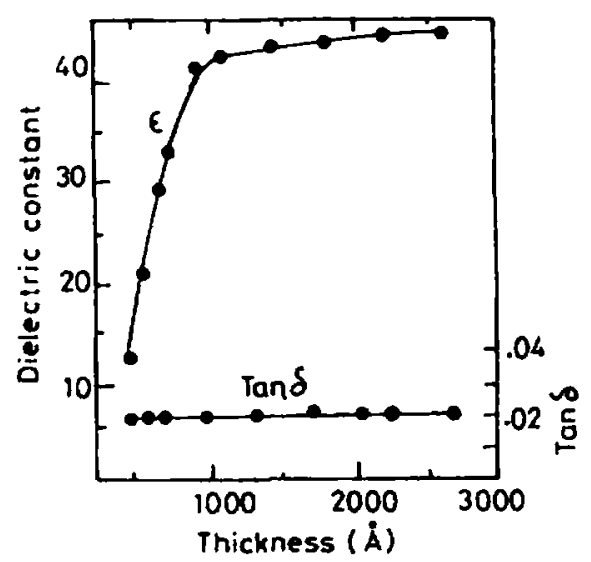

Fig. 1. Variation in dielectric constant and loss factor with dielectric film thickness.

The variation in dielectric constant with frequency at different temperatures is shown in Fig. 2. The variation in $\varepsilon$ is small at room temperature while at higher temperatures $\varepsilon$ displays a minimum and at lower and higher frequencies it increases. Figure 3 shows the variation in capacitance wth temperature at different fixed frequencies. The temperature coefficient $\gamma_{\mathrm{c}}$ of capacitance is defined as $(1 / C) \mathrm{d} C / \mathrm{d} t . \gamma_{\mathrm{c}}$ is also given by the relation

$$
\gamma_{s}=A \tan \delta-\alpha \varepsilon
$$

where $A$ is a constant for all practical purposes which can be taken as $0.05 \pm 0.01 \mathrm{~K}^{-1}$ 

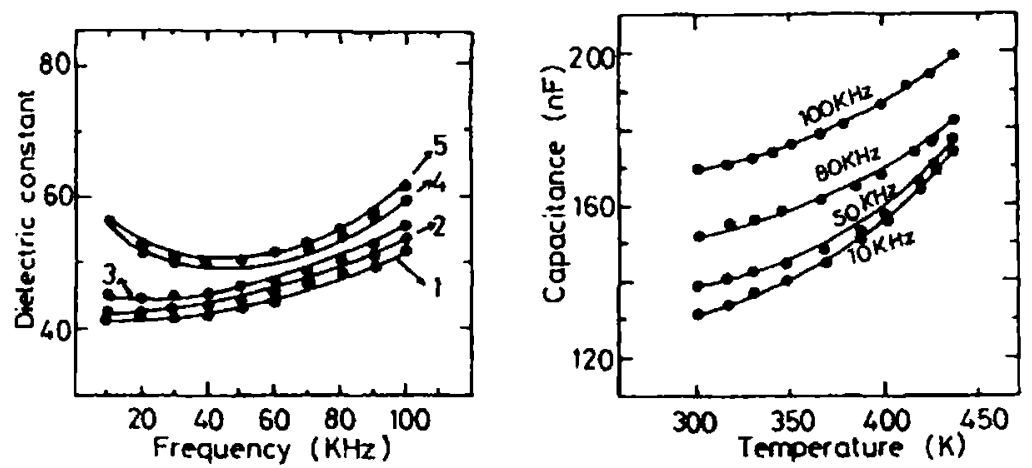

Fig. 2. Dependence of dielectric constant on frequency for $\mathrm{Sm}_{2} \mathrm{O}_{3}$ films at different temperatures (film thickness. $1100 \mathrm{~A}$ : curve $1.300 \mathrm{~K}$; curve $2.338 \mathrm{~K}$ : curve $3.370 \mathrm{~K}$; curve $4.415 \mathrm{~K}$; curve $5.438 \mathrm{~K}$.

Fig. 3. Capacitance us. temperature at different frequencies $\left(\mathrm{Sm}_{2} \mathrm{O}_{3}\right.$ film thickness, $\left.1100 A\right)$.

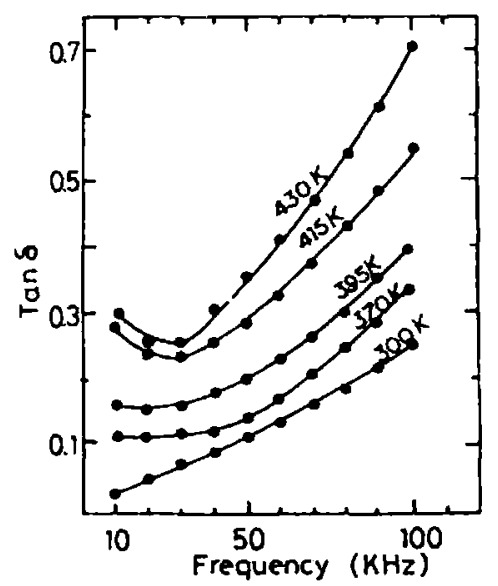

Fig. 4. Variation in $\tan \delta$ with frequency at different temperatures $\left(\mathrm{Sm}_{2} \mathrm{O}_{3}\right.$ film thickess, $\left.1100 \AA\right)$.

and $\alpha \varepsilon$ is the linear expansion coefficient. Typical values of $\alpha \varepsilon$ lie in the range $10-60 \mathrm{ppm} \mathrm{K}^{-1}$, which may be neglected in comparison with the error in the coefficient $\boldsymbol{A}$. The calculated value of $\gamma_{c}$ (minimum) at room temperature and at $10 \mathrm{kHz}$ is $1000 \mathrm{ppm} \mathrm{K}^{-1}$. From the graph the value of $\gamma_{\mathrm{c}}$ is obtained as $1300 \mathrm{ppm}$ $\mathrm{K}^{-1}$. The $\tan \delta$ value is found to decrease with increase in frequency and attains a minimum value which itself decreases at higher temperatures (Fig. 4). At lower temperatures the variation in $\tan \delta$ with frequency is less marked. X-ray studies show that the films obtained are essentially amorphous in nature. No indication of crystallinity were observed for films deposited at $453 \mathrm{~K}$. Generally amorphous films are continuous and thermal evaporation produce porous films below a film thickness of $200 \AA$. Therefore the measurements were taken only for films of thickness above $500 \AA$. The breakdown field strength $F_{b}$ is of the order of $10^{6}$ $\mathrm{V} \mathrm{cm}$ '. The breakdown strength is found to decrease with increase in film thickness 
and follows the Forlani-Minnaja relation ${ }^{11} F_{\mathrm{b}} \propto t^{-1 / 2}$. This indicates that the films are continuous and smooth and if discrete film defects and interface roughness exist the breakdown field strength is expected to decrease more rapidly ${ }^{12}$ at lower film thicknesses. Hence the observed dependence of the dieletric constant for films less than $1000 \AA$ thick is apparently due to defects such as voids, stress and inhomogeneities which are normally present in vacuum-deposited films rather than due to nonstoichiometry of the deposits resulting from excess of oxygen or metal ions. As the films become thicker, the density of voids decreases ${ }^{13}$, resulting in a higher value of dielectric constant which evidently becomes thickness independent. The stress resulting from the difference in thermal expansion coefficients of the film and substrate and that from the structure and growth of the films, which are generally found to have a thickness dependence, may also contribute to the dependence of $\varepsilon$ on film thickness. A theoretical analysis by Kornyshev et al. ${ }^{14}$ suggests that the observed effect was too large to be ascribed to the non-local nature of the dielectric response alone and the presence of voids and other inhomogeneities contributes to the observed anomaly in rare earth oxide films. The observed dependence of $\varepsilon$ and $\tan \delta$ on frequency and temperature may be accounted for by considering the equivalent circuit proposed by Goswami and Goswami ${ }^{15}$. This comprises an inherent capacitive element $C_{\mathrm{i}}$ unaffected by frequency and temperature, a discrete resistance $R$ which is assumed to be temperature dependent and parallel to $C_{i}$, and a series resistance $r$ due to the lead resistance. The effective capacitance with the series resistance increases with decreasing frequency when $R$ is small ${ }^{15}$. The decrease in $\tan \delta$ with frequency at a high temperature may be similar to the effect of the shunt resistance $R$. On the contrary, when the temperature is low the shunt resistance $R$ can be neglected and the rise in $\tan \delta$ at high frequencies is probably due to electrode resistance.

The current-voltage $1-V$ measurements of $\mathrm{Sm}_{2} \mathrm{O}_{3}$ films exhibit three distinct regions. At low fields conduction is ohmic $(I \propto V)$ and at higher fields it becomes trap-filled space-charge-limited conduction $\left(I \propto V^{4}\right)$. From the plot of $\ln \sigma v \mathrm{vs} .10^{3} / T$ the activation energy is calculated to be $0.05 \mathrm{eV}$. The low activation energy and the observation of trap-filled space-charge-limited conduction at higher fields suggest the presence of shallow traps.

\section{CONCLUSION}

The dielectric properties of electron beam evaporated $\mathrm{Sm}_{2} \mathrm{O}_{3}$ films prepared at a substrate temperature of $453 \mathrm{~K}$ include a high dielectric constant and good stability. The films are suitable for device application and have been successfully made use of in low voltage operated a.c. thin film electroluminescent devices ${ }^{16}$ in metal-insulator-semiconductor-metal structures.

\section{ACKNOWLEDGMENT}

One of the authors (M.K.J.) wishes to thank the University Grants Commission, New Delhi, for the award of a fellowship. 


\section{REFERENCES}

1 U. Saxena and O. N. Srivastava. Thin Solid Films. 33 (1976) 185.

2 V. M. Koleshko and N. V. Babushkina, Thin Solid Films, 62 (1979) I.

3 H. Nakane, A. Noya. S. Kuriki and G. Matsumoto. Thin Solid Films, 59 (1979) 291.

4 V.S. Dharmadhikari and A. Goswami, Thin Solid Films. 87 (1982) 157.

5 M. K. Jayaraj and C. P. G. Vallabhan. Thin Solid Films, 177 (1989) 59.

6 J. Ohwaki. H. Hozawaguchi and J. Tsujiyama. J. Appl. Phys., 22 (1983) 1133.

7 M. K. Jayaraj and C. P. G. Vallabhan, Bull. Elcctrochem. 5 (1989) 284.

8 R. M. Goldstein and F. M. Leonhard. Pror. Electronic Componenis Con/.. Washingion. DC. 1967. IEEE. New York. 1967, p. 312

9 G. Hass, J. B. Ransey and R. Thun, J. Opt. Soc. Am., 48 (1988) 324.

10 A. Goswami and R. Ramesh Varma. Thin Solid Filnus, 28 (1975) 157

11 F. Forlani and N. Minnaja, J. Vac. Sci. Technol., 6 (1969) 518.

12 N. Schwartz and R. W. Berry. Phis. Thin Films. 2(1964) 400.

13 K. L. Chopra. Thin Film Phenomena, McGraw-Hill, New York. 1969. pp. 189. 466.

14 A. A. Kornyshev, M. A. Vorotyntsev and J. Vistrup. Thin Solid Films, 75 (1981) 105.

15 A. Goswami and A. P. Goswami. Thin Solid Film.s, 16 (1973) 175.

16 M. K. Jayaraj and C. P. G. Vallabhan, Phys. Stutus Solidi A. 144 (1989) K 233. 